\title{
Designing for Interaction Immediacy to Enhance Social Skills of Children with Autism
}

\author{
Monica Tentori \\ Department of Informatics \\ University of California, Irvine \& \\ School of Computer Science \\ UABC, Ensenada \\ mtentori@uabc.uci.edu
}

\author{
Gillian R. Hayes \\ Department of Informatics \\ University of California, Irvine \\ gillianrh@ics.uci.edu
}

\begin{abstract}
Children with Autism Spectrum Disorder often require therapeutic interventions to support engagement in effective social interactions. In this paper, we present the results of a study conducted in three public schools that use an educational and behavioral intervention for the instruction of social skills in changing situational contexts. The results of this study led to the concept of interaction immediacy to help children maintain appropriate spatial boundaries, reply to conversation initiators, disengage appropriately at the end of an interaction, and identify potential communication partners. We describe design principles for Ubicomp technologies to support interaction immediacy and present an example design. The contribution of this work is twofold. First, we present an understanding of social skills in mobile and dynamic contexts. Second, we introduce the concept of interaction immediacy and show its effectiveness as a guiding principle for the design of Ubicomp applications.
\end{abstract}

\section{Author Keywords}

Interaction immediacy, social compass, social skills, autism

\section{ACM Classification Keywords}

K.3.1 Computer Uses in Education; K.4.2 Social Issues, Assistive technologies.

\section{General Terms \\ Design, Human Factors}

\section{INTRODUCTION}

Children with Autism Spectrum Disorder (ASD) often exhibit social impairment including difficulties in reciprocal social interaction, emotional expression, and emotional recognition [1]. These impairments often include problems initiating verbal interactions using appropriate greetings [2], challenges with establishing joint attention [3], and inability

Permission to make digital or hard copies of all or part of this work for personal or classroom use is granted without fee provided that copies are not made or distributed for profit or commercial advantage and that copies bear this notice and the full citation on the first page. To copy otherwise, or republish, to post on servers or to redistribute to lists, requires prior specific permission and/or a fee.

UbiComp'10, September 26-29, 2010, Copenhagen, Denmark.

Copyright 2010 ACM 978-1-60558-843-8/10/09...\$10.00. to engage in physical interactions such as joining a moment of spontaneous play [4].

Social skills training is an effective way to develop age and functioning-level appropriate social skills to be used in a variety of situations [5]. Many interventions for children with ASD, including those focused on the development of social skills, include the use of visual supports- "those things we see that enhance the communication process" [6]. Use of visual artifacts can reduce the symptoms associated with autism [7]. Specifically, Social Stories [8, 9], video modeling [10], and The Power Card [11] use visual tools to teach children about social situations, appropriate responses in those situations, and social protocols. Story-based interventions [8] are particularly compelling in their ability to go beyond developing basic social skills, including issues related to how situational contexts evolve in ongoing social interactions [8].

The Social Compass is a behavioral and educational intervention for group settings that uses stories and paperbased visual cues that, like a compass, serve to "steer the child in the right direction" [12]. Although this intervention has been used successfully in schools with demonstrated positive outcomes, there are still open questions as to how the children might apply their newly learned skills outside the classroom. However, there is currently limited support for this kind of mobile, dynamic instruction and support.

In this paper, we explore how innovative computing technologies can enable use of the Social Compass curriculum outside classrooms. We first describe other technological tools for children with ASD, focusing particularly on social engagement and development of social skills. We then describe an observational study of fourteen children with ASD and their interactions with peers, teachers, and aides at school. Based on the results of this study, we describe the pieces of contextual information that can be used to guide children in their social interactions and from these define the concept of interaction immediacy. We then present scenarios of use and design principles for developing Ubicomp tools for interaction immediacy. To exemplify the effectiveness and feasibility of our framework, we describe a design concept we call the 
Mobile Social Compass, a mobile augmented reality application that provides children with social cues and support during social interactions. We close by discussing how the concept of interaction immediacy may be used to benefit other populations and suggest opportunities for future work.

\section{RELATED WORK}

Many other researchers and practitioners have been focused on developing technologies to support the development of social skills. Riedl et al. developed Graphical Social Stories, a social skills learning game for adolescents with high-functioning autism spectrum disorder diagnoses based on social scenarios developed through a combination of human authoring and artificial intelligence [13]. Similarly, Bernard-Opitz et al. propose the use of animated solutions to common social challenges and situations in the "I Can Problem Solve" system [14].

In addition to structured scenario, storyboard, and animation interventions, other researchers have used animated characters and virtual reality. Virtual characters can be more predictable than human beings and may also be more patient in their teaching, thus supporting virtual learning [15]. By simulating the physical world, virtual reality technologies can support skill generalization [16] and enable collaborative interactions in a safe environment [17].

Most relevant to this current work, however, are tools designed to be worn or carried by an individual with ASD to support just-in-time, situated learning. The emotional hearing aid builds on work in detection of facial affect [18] to automatically indicate one of six emotional states to the individual wearing the aid [19]. Further developing this thread of research, Madsen et al. developed a learning tool that focuses on teaching the detected facial affect states to the individual using the tool [20]. Our work differs from the related literature in this area in that our tools explore the applicability of augmented reality to teach children about the physicality and temporal patterns in their social interactions, more so than conversational or affective elements.

\section{THE SOCIAL COMPASS}

The Social Compass is a social skills curriculum based on cognitive and behavioral theory [21]. This curriculum was developed by autism experts in Southern California over the last ten years and has been tested with thousands of students. The majority of the students enrolled in the Social Compass intervention are diagnosed as high functioning and so fit with the recommendations of Rao et al. for social skills curriculum to focus on developing generalizable skills in this population [22].

\section{Teaching Modules}

The Social Compass curriculum includes 26 lessons divided into four modules: Nonverbal Communication; Emotion; "We" Skills; and Social Problem Solving. The four modules, like a compass that guides North, East, West, and South serve to "steer the child in the right direction" [10].
The Nonverbal module focuses on observation of the body language and gestures of other children, recognition of spatial boundaries, detection and adjustment of tone of voice and eye contact. In the Emotions module, children learn to identify the intensity of their feelings, grow their ability to express empathy, and engage in positive self-talk ${ }^{1}$. The We skills module focuses on initiating or joining a conversation, asking questions, sharing information, and expanding personal interests. Finally, the Social problemsolving module helps children to stay on topic, pay attention and deal with being "left out" of a group. Together, these four packages aim to provide a collection of directions about what to do in social situations.

Each lesson is composed of eight steps. The materials for each lesson include instructions, a story, a visual support (Figure 1a), a reading comprehension worksheet, a selfmonitoring data sheet (Figure 1b), and a parent follow-up page. These tools help students associate stories with visual cues to learn particular social skills. The goal of the lessons and associated materials is to help students gain a deeper understanding of the use of the newly learned skill in different social contexts.

\section{A PROTOTYPICAL LESSON}

To more clearly illustrate the Social Compass curriculum, we provide an example of a single lesson: Space and Proximity. The instructor begins the lesson by writing the steps on the blackboard. Then, the whole group follows the steps together.

Step 1. The goal. The teacher acclimates the students to the curriculum format, introduces the goal of the lesson and its importance when developing social relationships. For this lesson, students practice how to determine the appropriate distance between them and other people.

Step 2. Visual gear. The teacher demonstrates the visual gear of the lesson through an image (i.e. the visual gear) that illustrates the key points of the lesson. An example of visual gear is a compass that draws concentric circles to illustrate the appropriate spatial boundaries to family, friends, acquaintances, and strangers (Figure 1a). During this step, the teacher explains each figure and discusses that the physical distance between people is often determined by their relationship to one another.

Step 3. Social story. The teacher and students read a social story and engage in a discussion of the story to ensure comprehension. The story of this lesson is about a child who comes too near a stranger's baby. Recognizing the mistake, the child immediately apologizes and, from that point on, keeps an appropriate distance from the baby.

After reading the story, the teacher goes through the following comprehension questions with the students, answering as individuals in a group chorus:

\footnotetext{
${ }^{1}$ Self-talk is a term used by teachers and therapists to describe the behavior of making positive statements to and about one's self.
} 


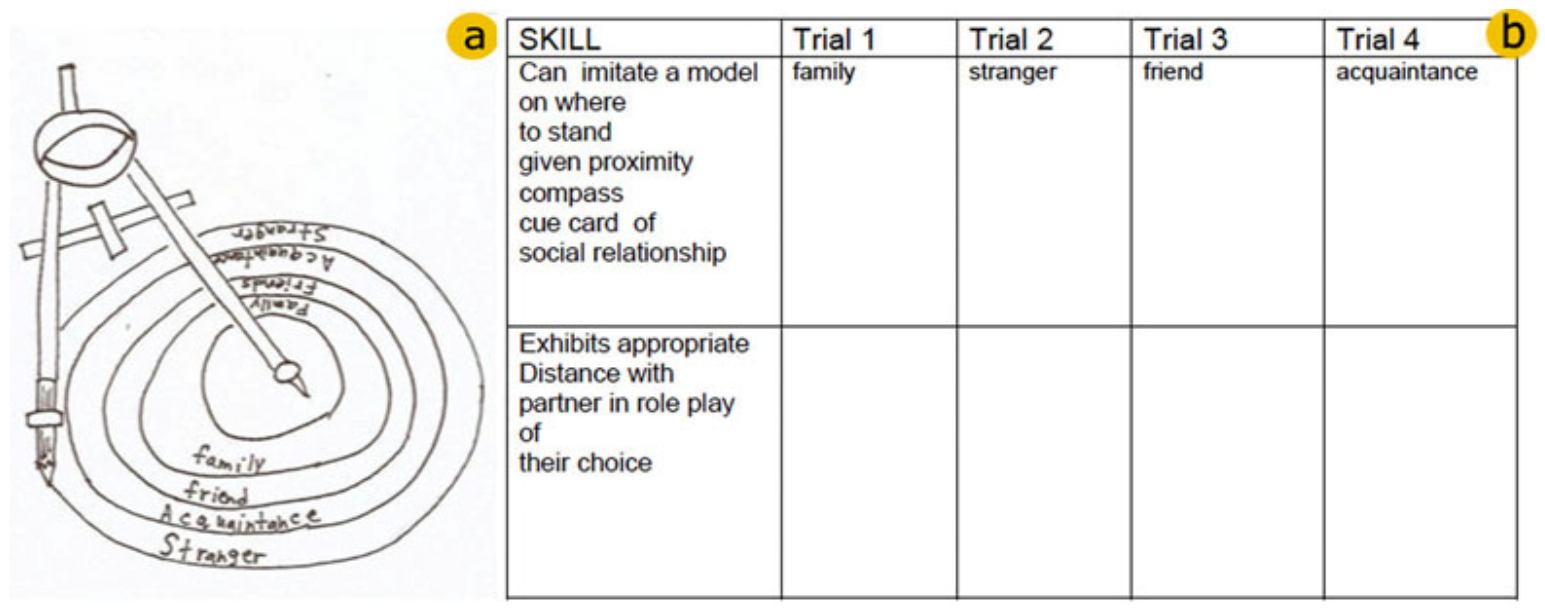

Figure 1. Tools during a lesson of social compass. (a) The proximity compass visual gear (b) The self-monitoring data sheet

- Who is the story about? Spencer

- What is his problem? He gets too close to the stranger's baby.

- What does he learn to do? Respond immediately (apologize) and check his proximity.

- Summarize. Spencer gets too close to a baby, and she cries. He learns to keep his distance and wave.

Step 4. Model. The teacher uses physical objects or her own body to demonstrate the skill. For this lesson, the teacher uses her body to demonstrate how close you should stand to a family member (touching to $1 / 2$ arm-length), friend (1/2 to 1 arm-length), acquaintance (1 arm-length), and stranger (2 arm-lengths).

Step 5. Rehearse. The teacher and students stand in a circle to rehearse the model in pairs. For this lesson, each student uses a cue card that denotes the relationship between him and his peer, such as family, friend, acquaintance or stranger. The students alternate practicing their new skills.

Step 6. Role Play. Each student chooses a peer to rehearse the social skill of the lesson in front of the group. In this lesson, each student must role play all four potential scenarios while the rest of the students provide feedback in the form of a "thumbs up" when the skill was successfully portrayed or "thumbs down" when not.

Step 7. Reinforcement and feedback. After the role-playing session, the students rate themselves on the self-monitoring data sheet (Figure 1b) on a scale of one to three, with three indicating a successful portrayal of the skill.

Step 8. Generalization. The teacher provides praise or further instructions as appropriate. At the end of the lesson, the teacher provides a handout with scenarios for practicing the social skill outside the classroom.

UNDERSTANDING SOCIAL SKILLS OF CHILDREN WITH ASD IN MOBILE CONTEXTS

For five weeks, we conducted an observational study to supplement our understanding from the literature of the problems high-functioning children with ASD face during social interactions. This study was conducted in three public schools that use the Social Compass curriculum. Researchers video recorded fourteen children (aged 8 to 10, 2 female) during recess ${ }^{2}$ and lunch for an average time of 15 minutes per child per day. Mobile structured observation techniques [23] were used to capture the data including shadowing individuals and recording their actions as executed. We later conducted detailed analysis of the video looking for both expected activities and allowing new observations and themes to emerge from the data. The total time of detailed observation was approximately 15 hours. To complement our observational study, we also conducted interviews with three teachers and the autism coordinator, and the first author was trained in the Social Compass intervention. In the following sections, we draw from our observations, videos and field notes to discuss the results of this study and its implications for the design of technologies to support mobile social skills training.

\section{Social Interactions and Encounters}

Individuals with autism demonstrate deficits in both receptive and expressive language [1]. Similarly, we observed students experiencing difficulties with both passive and proactive interactions, which the Social Compass intervention is explicitly designed to support.

Passive interactions include those situations in which the child is primarily receiving instruction or communication and remaining intentionally inactive adopting a "wait-andsee" behavior. Among these interactions, we included times when the child is paying attention, being left out or receiving instructions. Specifically, paying attention refers to those actions when the child is observing the execution of an interaction but not participating in it (Figure 2a). If the child is further disengaged and no longer in the student group, we consider him left out. Receiving instructions

\footnotetext{
${ }^{2}$ In the United States, recess refers to a break or playtime children have once or twice during each school day. Typically, the students will leave the classroom and spend recess at the playground.
} 
refers to an interaction in which a caregiver guides a child, but the child is not active in the instruction.

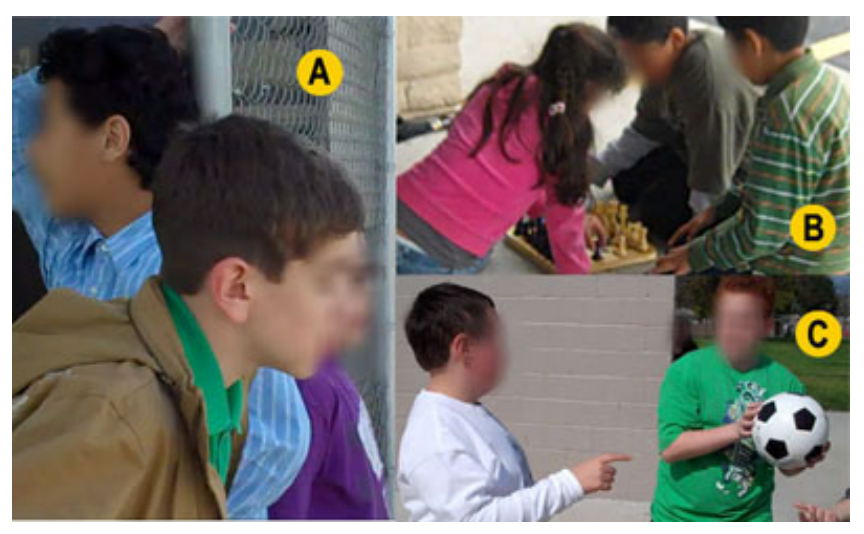

Figure 2. Children during a day of observation. (a) Three children with ASD engaged in passive interactions (b)

Children with ASD engaged in a physical interacting (c) Children with ASD engaged in a verbal proactive interaction.

In contrast, proactive interactions are those interactions that require a child to be forthcoming and engaged in a social situation. These interactions include asking questions (Figure 2c), sharing information, giving compliments, maintaining a conversation, engaging in a physical interaction, or negotiating needs. For example, a child is engaged in a physical interaction when he joins a physical game (e.g., chess, Figure $2 b$ ) and remains playing until the game is finished.

In our observations, children with ASD who are typically engaged in passive interactions remain isolated. However, even children with ASD who engaged in proactive interactions continually switched among proactive and passive modes of interaction, as opposed to remaining engaged in proactive interactions for extended periods.

\section{Interaction Immediacy}

Temporal rhythms, social missteps and proximity in activity and relationship are all social cues that children with ASD can use to:

- maintain appropriate space proximity,

- instant reply ${ }^{3}$ in a conversational context,

- avoid interaction ruptures, and

- identify potential interaction partners.

By taking into account these social cues, children can anticipate social situations, see them as opportunities rather than threats, and influence the interaction constructively instead of only passively reacting to it. Thus, we define interaction immediacy as the social cues that can provide adequate indication of potential interactions, promote

\footnotetext{
${ }^{3}$ The "instant reply" concept mimics the sports media service of replaying a game play in slow motion. It is used in the social compass intervention to help students understand the internal processes that occur in social situations by "rewinding" and replaying scenes.
}

proactive interactions, and allow for rapid and sustained engagement given different social contexts.

The role of proximity-based location and temporal rhythms in interaction immediacy

The physical proximity of other children often indicates potential social interaction partners. For instance, most interactions are initiated when children leave the classroom for the playground. At this time, the children are positioned very close together, often walking in pairs. They make informal plans for recess activities. Thus, if a successful interaction is achieved during this time, the students involved will often continue to engage in interactions during recess. For instance, during a day of observation:

When Steve 4 was walking towards the playground, he picked up a ball. His friend Scott asked him if they could play together. That day during recess, they spend most of their time playing together.

However, sometimes children with ASD get "lost," triggering a rupture in an ongoing interaction. For instance, from our study:

While Mike was playing ball, a child close to him shouted and, as a consequence, Mike became scared and ran into the bathroom. Ian was not able to finish the game with Mike and remained confused, asking other kids about Mike's behavior. That day, Mike never got back to the playground and spent the rest of the recess walking around the school premises.

From scenarios like these, we observed that each interaction exhibits a three-way handshake $\mathrm{e}^{5}$ behavior. First, a peer starts an interaction; second, the interaction is acknowledged and eventually will to reach its climax; and third, the interaction is ended. If these kinds of three-way handshakes do not occur, the interaction ruptures.

A child's proximity can serve as an interaction beat used to detect each step of the three-way handshake. Gonzalez et al. used these beats to detect artifacts behavior and used them for activity recognition [24]. We define a roaming beat as the ability of a child to, given a time stamp, move outside of the interaction proximity range or come back into it. In this case, a beat acts as a temporal rhythm marker determining the current step of the three-way handshake. For instance, the following scenario illustrates the roaming beats of an interaction between Mike and Ian:

Initiating an interaction [first beat-first handshake]: Mike and Ian start playing ball and set a distance between them determining the interaction proximity range (IPR).

Acknowledging an interaction [second beat-second handshake]: Mike throws the ball to Ian, and he stays in the IPR.

\footnotetext{
${ }^{4}$ All names have been changed to deintify research informants.

${ }^{5}$ The three-way handshake references the behavior of the TCP protocol in networking as a metaphor for this exchange.
} 
Ending an interaction [third beat-third handshake]: Ian receives the ball and laughs, staying in the IPR.

\section{Initiating an interaction [fourth beat-first handshake]: Ian throws the ball back to Mike, and he stays in the IPR.}

Acknowledging an interaction [fifth beat-second handshake]: Mike hears a child shouting and runs towards the bathroom. He leaves the IPR. No acknowledgment is achieved.

Breaking an interaction [sixth beat-second handshake]: After a while, Mike does not return and Ian does not leave the IPR because he is waiting for Mike. After Mike does not return to the IPR for an extended period, the three-way handshake principle is no longer satisfied.

Indeed, these roaming interaction beats act as temporal patterns that characterize the natural execution of an interaction (i.e., when an interaction starts, ends and it is maintained). These results build upon the observation of previous studies in different settings that highlight that temporal patterns or "rhythms" are often used to coordinate activities and contribute to the regular temporal organization of work [25] and could characterize the levels of work fragmentation [26].

The role of interaction immediacy closeness in proximitybased relationship and activity

In addition to choosing from among the pool of nearby potential interaction partners, children with ASD - like their neurotypical peers - make these choices based on their relationships and the match between activity choices of others and their own preferences (e.g., choosing to interact with a child who is playing chess because you like chess).

Social proximity describes the level of closeness to family, friends, acquaintances, and strangers. In this case, the level of closeness determines both adequate physical proximity and the type of information that the child should share with them. These results build upon other studies that highlight that social serendipity [27] and shared interests [28] could be used to prompt informal, face-to-face interactions between nearby users. In our study, children with ASD used this information as a means for detecting potential interaction partners and understanding the appropriate way to approach these individuals.

Activity proximity describes a match between the preferences of individual children and the activities being executed by others. In this case, the level of closeness enables selection of the group or individual whose activities might be most exciting or desirable to join. Of course, these preferences are dynamic over time and may even vary within a given day, making the description of this type of proximity extremely challenging. In our observations, teachers translated activity preference into a physical location sensor of sorts as well, knowing for example, that a child who likes to play chess will typically be found near the board game tables where other children play chess.

Both relationship and activity proximity influence the likelihood of a successful interaction with another person. Furthermore, these indicators can help identify a potential interaction partner.

\section{Interaction immediacy to detect social missteps}

During an interaction, children with ASD might inadequately use body language in a way that may make others feel uncomfortable and, as a consequence, interrupt or terminate the interaction. We identified this inappropriate use of body language or non-verbal skills as a social misstep. The missteps observed in our data include using an inappropriate tone of voice or volume level (e.g., shouting), avoiding eye contact or making too much (e.g., staring), invading personal space, and interrupting or breaking an interaction. For instance, during a day of observation:

While Sam was playing ball with Meg, he accidentally hits Leslie when running towards the ball. Sam did not apologize to Leslie and she remains confused about Sam's behavior.

In our observations, teachers sometimes followed students to provide additional instructions for avoiding such missteps or catching them before they escalate into major incidents. When significant incidents do occur, often following multiple smaller missteps, other children often responded by laughing, teasing, or "tattling on" the student who made the misstep. These kinds of incidents can make children with ASD feel misplaced in the social context of the school and remain isolated. Awareness of potential missteps - currently provided by teachers-enables students to join groups and engage in proactive interactions.

\section{DESIGNING FOR INTERACTION IMMEDIACY}

In this section, we discuss some scenarios and design principles that show the feasibility and applicability of designing for interaction immediacy. These principles and scenarios were derived from the results of our study.

\section{Exploiting interaction immediacy scenarios}

Interaction scenarios provide means for envisioning how interaction immediacy can be used for the development of Ubicomp applications to augment social skills for children with ASD.

\section{Scenario 1: Interaction immediacy to promote proactive interactions and encounters}

This scenario illustrates how children with ASD might use the proximity compass and the shared interests gears of the social compass curriculum to identify potential communication partners, expand their interests and tag mementos.

David is a nine year-old child with ASD who likes to play chess and basketball. While walking around the playground, he receives an alert from his Mobile Social Compass notifying him that some other students nearby are playing chess. He consults the 


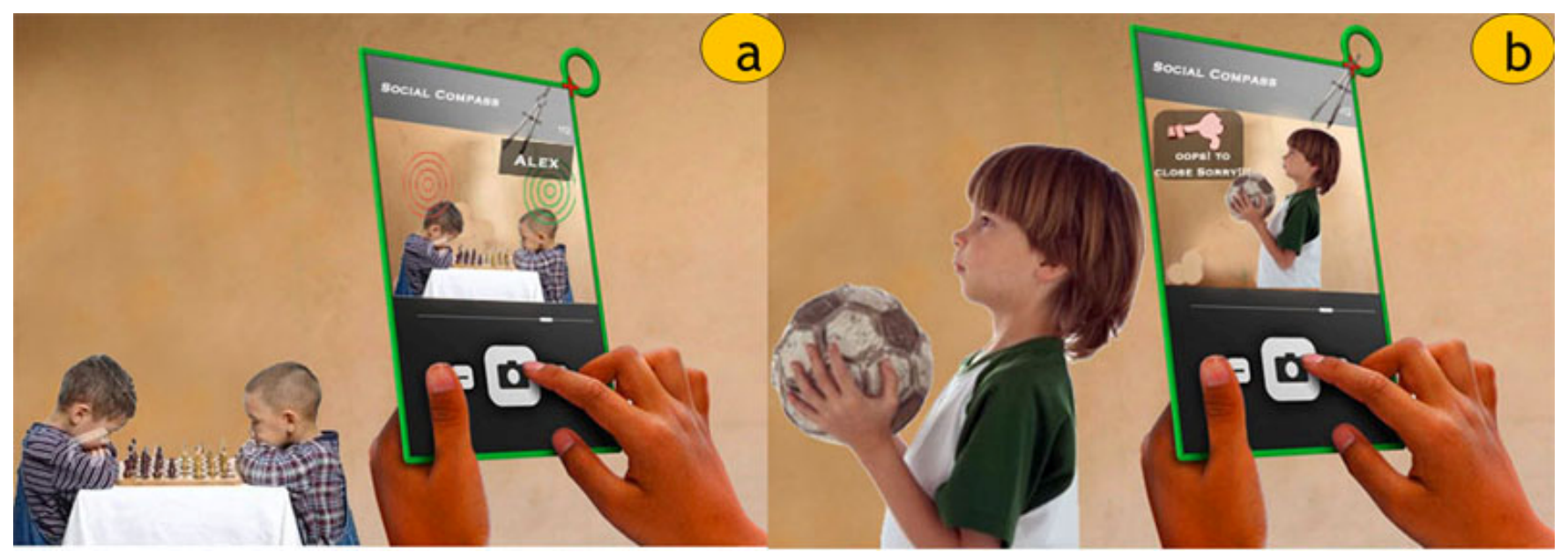

Figure 3. The Mobile Social Compass Mockup. (a) A child using the mobile compass to detect social relationship proximity. (b) The mobile compass notifying the child of a social skill hazard.

system and learns that the chess players are at the playground. He moves to the playground and, upon arrival, his Compass points to his friend Alex and a stranger, who are playing chess (see Figure 3a). This augmented digital visual gear corresponds to the visual gear David learned to use during his Social Compass therapy. He also learns through a visual cue on the device that the stranger's name is Ethan, and they share an interest in basketball. When David arrives at the playground, the system suggests him to give Alex a game advice and, it also suggests that he share his basketball interests with Ethan. Both realize that they like the Lakers and Kobe Bryant. Next, David uses the system to tag a photo with the common interests shared with Ethan.

\section{Scenario 2: Detecting and handling missteps}

This scenario illustrates how the system detects missteps and provides guidance to children with ASD, including conversational elements that should be used when an incident occurs.

Mike, an eight year-old child with autism, is playing ball with his friend Ian. While running towards the ball, Mike accidentally bumps into John. Mike's Mobile Social Compass detects this misstep and sends him an alert giving him a "thumbs down," indicating that he is too close to John (Figure 3b). Mike immediately apologizes to John following the social cue provided to him by the system. John tells him not to worry. Instead of then returning to Ian, Mike heads towards the playground. The system alerts Mike with a "thumbs down," because he has not finished the game with Ian nor returned the ball to him. Recognizing his mistake, Mike turns back to Ian and continues playing until recess ends.

\section{Interaction immediacy design principles}

Using the results of our study and the above scenarios, in this section, we describe a set of design principles that
Ubicomp applications must incorporate to provide interaction immediacy.

\section{Detecting activity and relationship proximity}

Children with ASD can use activity and relationship proximity to detect potential collaborations and the proper amount of personal information to share with others. Applications exhibiting interaction immediacy must then be able to discover potential interaction partners, much like "friend finder" applications [29]. In contrast with previous applications in the literature, to support interaction immediacy this discovery service must take into account both activity and relationship proximity. For example, as shown in the first scenario, David decides to join Ethan and Alex because he is aware that they are playing chess, and this activity matches David's interests. The relevance of Ethan and Alex's activity to David's interests persuades him to proactively start an interaction.

Additionally, knowing the relationship with others allow children with ASD to discover which individual is the best person in the group with whom to start an interaction. For example, in the first scenario, David started an interaction with his friend. To infer potential communication partners and their context (such as activity, location and proximity), designers must develop approaches for identifying what information to sense, the appropriate sensing technologies to utilize, and a way to model different levels of activity and relationship proximity.

Augmenting stories with visual cues and social cues

Often, children with ASD learn social skills through stories and visual images. Thus, a system must be able to provide social cues that portray a story and link it to a representative image. We argue that such a story should portray the real context in which the interaction is being held as a dimensional picture that depicts the same scene a child can physically see, as technologies for augmented reality do [30]. This picture should then be enhanced with visual cues that depict a social skill relevant to such interaction, as the visual gear used in the Social Compass curriculum do. For 
instance, in the first scenario, Mike detects his relationship with Ethan and Alex and the appropriate spatial proximity and boundaries for both of them through a photo augmented with the social compass gear (Figure 3a). In this case, the children with ASD will be able to see invisible meta-data in the social situation that he can use as cues when interacting with others. These scenes should also provide verbal cues that help the child instantly reply, given a particular social situation. For instance, in the second scenario, the system detects a proximity misstep and suggests that Mike apologize to John. Thus, a social cue must include:

- a desirable story from real life portraying the context of a social interaction,

- a set of predefined phrases for different social contexts to give guidance to the use and promote instant replies,

- feedback to rate and report on a child's behavior, and

- visual cues to give a child social directions.

This functionality also requires a context representation model allowing the representation of social cues at different levels of granularity, depending on the interaction context.

\section{Providing awareness of missteps}

Awareness of potential social missteps can help avoid incidents when interacting with others. Thus, applications should detect these missteps and notify the user when they occur, providing him with social cues and instructions for recovering from them. For instance, in the second scenario, the phone shows "thumbs down" to Mike when he invades John's space, while providing, as a social cue, an apology phrase: "Oops!! Too close, sorry!!" Besides helping to manage non-verbal missteps, an application must also be able to monitor the three-way handshake principle of an interaction. Thus, the application must be able both to sense and to influence social interactions without interfering with the children's activities and current interactions.

\section{Tagging memorabilia}

Every time children with ASD are engaged in social interactions, they expand their knowledge about how the social context might affect or transform such interactions. They might even expand their vocabulary or interests about a particular topic. For instance, in the first scenario, David learns that Ethan also likes the Lakers and Kobe Bryant. A memento commemorating this moment could be useful when David finds himself in a similar social context. A system for interaction immediacy, thus, must be able to provide innovative ways that enable children to capture such situations and tag context or descriptions of memories associated with these mementos that could then evoke a social interaction in a given context. For instance, in the first scenario, David tags Ethan's interests in the social interaction scene captured by his phone. As Nunes stated: "tagging memorabilia to an object might trigger direct experiences where the item evoked a memory of a specific place or event, or indirect experiences, such as to serve as a reminder of one's heritage or as a reminder of the person that gave them the item" [31]. By capturing these mementos through photographs and attaching tags to them through a child's phone, the system can encourage opportunities for face-to-face interaction based on previously captured real-life, story-based scenes.

Furthermore, these snapshots can also enable teachers and caregivers to track a child's progress. As others have pointed out, documenting and understanding the progress of children with ASD is a significant goal for special educators and parents. Furthermore, our fieldwork indicates that tracking social skills data is particularly challenging $[32,33]$. Thus, these stakeholders could also use this information to monitor interesting social interactions events, activities or behaviors exhibited by children with ASD in natural and dynamic settings.

\section{DESIGNING THE MOBILE SOCIAL COMPASS SYSTEM}

In this section we present a concept design for a system that satisfies the design requirements resulting from our analysis, the Mobile Social Compass. This design concept includes a mobile augmented reality application that provides children with social cues to help them detect potential communication partners, promote proactive interactions, and instantly reply given a particular social context, particularly when that context includes a social misstep (see Figure 3).

\section{Identification of potential interaction partners and missteps}

To discover potential interaction partners, we must first estimate the proximity of other children and recognize their activities. To this aim we are exploring available solutions for activity and artifact recognition based on pattern recognition algorithms [34] or vision-based techniques [24]. Both approaches are based on information gathered from observational studies in which detailed observations are recorded and annotated.

Information about proximity can also used to discover social missteps during an interaction. For example, to infer when the child is invading the space of others based on his relationship the distance among children could easily trigger a misstep. Also, machine learning algorithms could be tuned to infer an interaction's proximity range and based on children's interaction beats decide when the three-way handshake is broken.

\section{Tagging memories}

A tagging service can enable children with ASD to enhance scenes from stories by adding metadata to provide more content and knowledge about a given scene. Tags are generally chosen informally and personally by the item's creator (or viewers) [35]. To simplify interaction, however, the Mobile Social Compass will restrict the tags' categories to an inventory of predefined items, such as personal interests, visual gear, and other students who might be interaction partners.

The tagging service enables the creation of memorabilia any time a child expands his knowledge about a particular social interaction and wants to preserve a memory of it. The additional metadata will also ease the retrieval of 
detailed information during similar situations in the future. For example, if David, from the first scenario, ran into Ethan, a memorabilia story will be displayed to David reminding him about their conversation about basketball.

New content, added directly by the child, can help caregivers identify whether the child was able to understand and generalize from an interaction, an important metric for learning a new skill. Furthermore, review of these memorabilia can help reinforce the lesson. This information could also be useful for improving the accuracy of available pattern recognition algorithms as learning opportunities particularly if the algorithm makes a mistake that is corrected by the child or a caregiver.

\section{Social cue prompting}

A prompting service can be used to create and deliver appropriate social cues by working in concert with the discovery service to ensure that cues are delivered at the appropriate time. To provide accurate suggestions, this service will need a representational model to depict a social cue in its digital form ${ }^{6}$ and then notify the user. Therefore, when the discovery service triggers a social cue, this service will retrieve a specific representation of a stored social cue. A multi-layered ontology for modeling a hierarchy of cues can be used to represent social cues. This approach echoes previous work for representing hospital [36] and elder activities [37]. The design of the ontology composes social cues from among a set of Stories and Phrases.

A Story is a picture used to depict the context of a social interaction. The Mobile Social Compass System can use digital photos automatically captured from the device itself, similar to the capture functionality of the SenseCam [38]. A story is composed of potential interaction partners and contextual information, such as the location and the activity portrayed. A social story may also have aggregated pointers, gear, and memorabilia. A pointer is a picture that gives feedback to the child about the correctness of social skills usage, either giving him "thumbs up" or "thumbs down" (Figure 3b). A piece of gear is an image that gives a child direction about how to approach a particular social situation. For instance, the proximity compass lets the child know the right space proximity between him and other people. Memorabilia is a set of stories that have previously been tagged with meaningful content.

In contrast, phrases can provide children with information to reply instantly in a particular situation. Each social cue should provide a set of phrases to be shown to the child when appropriate. Once the system retrieves a social cue's representational model it can use ringtones, earcons [39], or augmented reality icons to notify the child of an appropriate response given the situation (see Figure 3).

\footnotetext{
${ }^{6}$ A digital social cue is an array of contextual elements properly linked to notify to computational services content about a particular situation.
}

\section{CONCLUSIONS}

In this paper, we present results of an observational study of the challenges children with ASD face in developing and using social skills in mobile and dynamic contexts as well as the strategies they employ to overcome these challenges. Drawing on these results, we present the concept of interaction immediacy and a set of design principles as a framework for designing for interaction immediacy for Ubicomp applications. We validated both the concept and the framework through the design of the Mobile Social Compass, discussing issues arising from its future implementation. These kinds of systems can leverage successful strategies from educational and behavioral therapy alongside novel Ubicomp technologies to support children with ASD in improving their social skills in everyday life.

The primary contribution of this work was to articulate and explore the design space of interaction immediacy for a specific domain. However, applications that support interaction immediacy can also be useful to other populations, such as for eldercare or hospital work.

Elders, particularly those with Alzheimer's disease or other cognitive deficits, can require significant support for both memory and initiating and maintaining social engagements. Using an assistive technology built for interaction immediacy could help elders to avoid isolation and potentially to delay their cognitive decline, which can be heavily correlated to the lack of social interactions and size and engagement with their social network [37]. Likewise, one of the biggest challenges in hospital work is locating the right person to interact with in a given moment [26]. Applications for interaction immediacy could allow hospital workers to detect appropriate times to interrupt colleagues based on their activities, shared interests, or other workrelated shared contexts (e.g., shared or similar patients). Furthermore, these types of applications have the potential to increase opportunistic interactions that are essential for the adequate management of hospital work.

More research is required to explore significant open challenges related to the development and evaluation of systems built for interaction immediacy. Open questions remain concerning which level of proximity and activity recognition accuracy is needed, which notification mechanism will be more suitable and what is the impact of such systems on current practices. For instance, estimating a child's activity, with whom he is interacting or when a an inappropriate interaction has occurred, is challenging and available approaches require a priori calibration and configuration. In applications for interaction immediacy in which an immediate response and high accuracy is required, approaches that work "out of the box" by detecting collaboration or activities directly from sensors could be an appropriate solution.

This research also opens up new questions surrounding the impact of our application and other assistive technologies 
meant to be used by children with ASD in their everyday lives. Use of these technologies can raise concerns about liability, privacy, and the use and control of data for both the user of the assistive technology and for others involved. Furthermore, the levels of independence to be reached by those using the tools and the ways in which independent living is measured should be further interrogated. To this aim, we plan to deploy and evaluate a prototype version of the Mobile Social Compass at the public schools engaged during our field work.

\section{ACKNOWLEDGMENTS}

This work was supported by grants from AutismSpeaks Innovative Technologies for Autism, NSF CAREER grant \#0846063 and UC Mexus. We thank the participants in this work for their dedication and time as well as Khai Truong, Stephen Voida, and the STAR group at UCI for early reviews of drafts.

\section{REFERENCES}

1. American, P., Psychiatric Association (1994). Diagnostic and statistical manual of mental disorders (4th ed.). Washington, DC. 1994.

2. Hobson, R.P. and A. Lee, Hello and goodbye: A study of social engagement in autism. Journal of Autism and Developmental Disorders, 1998. 2(1): p. 117-127.

3. McArthur, D. and L.B. Adamson, Joint attention in preverbal children: Autism and developmental language disorder. Journal ofAutism and Developmental Disorders, 1996. 26(3): p. 481-496.

4. Libby, S., et al., Spontaneous play in children with autism: A reappraisal. . Journal of Autism and Developmental Disorders, 1998. 28(2): p. 487-497.

5. Bauminger, N., The Facilitation of Social-Emotional Understanding and Social Interaction in HighFunctioning Children with Autism: Intervention Outcomes. Journal of Autism and Developmental Disorders, 2002. 32(4): p. 283-298.

6. Hodgdon, L.A., Visual Strategies for Improving Visual Communication: Volume I: Practical support for school and home. . Quirk Roberts Publishing, 1999.

7. Cohen, M.D. and D.L. Sloan, Visual Supports for People with Autism: A Guide for Parents and Professionals, ed. B. Ed.D. 2008.

8. Gray, C., Social stories and comic strip conversation with children with Asperger Syndrome and High Functioning Autism. . In Asperger Syndrome or Highg-Functioning Autism? Schopler et. Al. (Eds.) Plenum Press, New York, 1998: p. 167-198.

9. Swaggart, B.L., et al., Using Social Stories to Teach Social and Behavioral Skills to Children with Autism. Focus on Autism and Other Developmental Disabilities, 1995. 10: p. 1-6.
10. Charlop-Christy, M.H., L. Le, and K.A. Freeman, $A$ Comparison of Video Modeling with In Vivo Modeling for Teaching Children with Autism. Journal of Autism and Developmental Disorders, 2004. 30(6): p. 537552.

11. Gagnon, E., The Power Card: Using Special Interests to Motivate Children and Youth with Asperger Syndrome and Autism. Autism Asperger Publishing Company., 2001.

12. Boyd, L., C. McReynolds, and K. Chanin, A StoryBased Intervention Package for Social Skills, N.O.C.S.E.L.P. Area, Editor. 2010: Fullerton, CA, USA. p. 190.

13. Riedl, M.O., et al. Graphical social scenarios: Toward intervention and authoring for adolescents with high functioning autism. in AAAI Fall Symposium on Virtual Healthcare Interaction. 2009. Arlington, VA.

14. Bernard-Opitz, V., N. Sriram, and S. NakhodaSapuan, Enhancing social problem solving in children with autism and normal children through computerassisted instuction. Journal of Autism and Developmental Disorders, 2001. 31(4): p. 377-384.

15. Tartaro, A. and J. Cassell. Playing with virtual peers: bootstrapping contingent discourse in children with autism. . in International Conference of the Learning Sciences. 2008.

16. do2Learn. http://www.dotolearn.com/. 2010.

17. Moore, D., et al., Collaborative Virtual Environment Technology for People With Autism. Focus on Autism and Other Developmental Disabilities, 2005. 20: p. 231-243.

18. El Kaliouby, R. and P. Robinson. Real-Time Inference of Complex Mental States from Facial Expressions and Head Gestures. in 2004 Conference on Computer Vision and Pattern Recognition Workshop (CVPRW'04). 2004.

19. El Kaliouby, R. and P. Robinson, The emotional hearing aid: an assistive tool for children with Asperger syndrome. Universal Access in the Information Society 2005. 4(2): p. 121-134.

20. Madsen, M., et al. Technology for just-in-time in-situ learning of facial affect for persons diagnosed with an autism spectrum disorder. in ASSETS. 2008.

21. Baron-Cohen, S., Precursors to a theory of mind: Understanding attention in others. In A. Whiten (Ed.), Natural theories of mind: Evolution, development and simulation of everyday mindreading. Oxford: Basil Blackwell. 1991.

22. Rao, P., D. Biedel, and M. Murray, Social skills interventions for children with asperger's syndrom or high functioning autism: A review and 
recommendations. Journal of Autism and Developmental Disorders, 2008. 38(2): p. 353-361.

23. Mintzberg, H., Structured Observation as a Method to Study Managerial Work. The Journal of Management Studies, 1970. 7(1): p. 87-104.

24. Gonzalez-Fraga, J., M. Tentori, and F. Martinez, Artifacts' Roaming Beats Recognition for Estimating Care Activities in a Nursing Home, PervasiveHealth, Editor. 2010: Munchen, Germany, March 22-25.

25. Reddy, M. and P. Dourish. A Finger on the Pulse: Temporal Rhythms and Information Seeking in Medical Work. in Computer Supported Cooperative Work. 2002. New Orleans, Louisiana: ACM.

26. Tentori, M. and J. Favela, Activity-aware computing for healthcare. IEEE Pervasive Computing, 2008. 7(2): p. 51-57.

27. Eagle, N. and A. Pentland, Social Serendipity: Mobilizing Social Software. IEEE Pervasive Computing, 2005. 4(2): p. 28-34.

28. Terry, M., et al. Social net: using patterns of physical proximity over time to infer shared interests. in Conference on Human Factors in Computing Systems, CHI '02. 2002. Minneapolis, Minnesota, USA.

29. Belloni, N., L.E. Holmquist, and J. Tholander. See You On The Subway: Exploring Mobile Social Software. In Work In Progress at CHI 2009. 2009. 9, Boston, USA.

30. Azuma, R.T., A Survey of Augmented Reality. Teleoperators and Virtual Environments, 1997. 6(4): p. 355-385.

31. Nunes, M., S. Greenberg, and C. Neustaedter, Using physical memorabilia as opportunities to move into collocated digital photo-sharing. Int. J. HumanComputer Studies 2009. 67: p. 1087-1111.

32. Hayes, G.R., et al. CareLog: a selective archiving tool for behavior management in schools. in Conference in Human Factors, CHI. 2008.

33. Kientz, J.A., et al., Pervasive Computing and Autism: Assisting Caregivers of Children with Special Needs. IEEE Pervasive Computing, 2007. 6(1): p. 28-35.

34. Sanchez, D., J. Favela, and M. Tentori, Activity recognition for the Smart Hospital. IEEE Intelligent Systems, 2008. 23(2): p. 50-57.

35. Van Den Hoven, E. and B. Eggen, Informing augmented memory system design through autobiographical memory theory. Personal Ubiquitous Computing, 2008. 12: p. 433-443.

36. Tentori, M., M. Rodriguez, and J. Favela, An agentbased middleware for the design of activity-aware applications. To appaera in IEEE intelligent Systems, (2010).

37. Garcia-Vazquez, J.P., et al., An agent-based Architecture for Developing Activity-Aware Systems for Assisting Elderly Journal of Universal Computer Science, (submitted).

38. Hodges, S., et al. SenseCam: A Retrospective Memory Aid. in Ubicomp. 2006.

39. Blattner, M., D. Sumikawa, and R. Greenberg, Earcons and icons: their structure and common design principles. Human Computer Interaction, 1989. 4(1): p. 11-44. 